\title{
TRANSGENERIDADE: UMA ANÁLISE DA REPRESENTAÇÃO DA IDENTIDADE DO EU E DO ESTIGMA NAS PRODUÇÕES AUDIOVISUAIS RECENTES ${ }^{1}$
}

\author{
TRANSGENERITY: AN ANALYSIS OF THE REPRESENTATION OF THE SELF \\ IDENTITY AND OF STIGMA IN RECENT AUDIOVISUAL PRODUCTIONS
}

\begin{abstract}
Resumo
Transgênero são pessoas que possuem a percepção de pertencer a um gênero que não condiz com o atribuído pela sua genitália de nascimento, nesta condição são estigmatizados pela sociedade, interferindo na sua identidade. Como forma de melhor experienciar seu modo de existência, essas pessoas buscam modificar seu corpo conforme sua percepção de gênero. Por essa perspectiva, o objetivo do presente trabalho foi identificar, nas produções audiovisuais recentes, como os transgênero interpretam e significam suas trajetórias ratificando sua identidade do eu sob a perspectiva de Erving Goffman. O artigo foi dividido em três partes. A primeira apresenta um recorte teórico acerca do universo trans em seus aspectos mais gerais. Na segunda está exposta a relação entre os transgênero e o modo como percebem e identificam sua identidade do eu. E na terceira são demonstrados os recursos utilizados pelos sujeitos trans como forma de adequar sua imagem a sua identidade desejada, se sentindo melhor consigo mesmo e mais aceito pela sociedade.
\end{abstract}

Palavras-chave: Transgênero. Identidade do eu. Estigma. Modificações corporais.

\begin{abstract}
Transgender people are those who perceive themselves as belonging to a gender that does not correspond to their genitalia at birth. Due to that, they are stigmatized by the society, which interferes in their identities. In order to improve their existence, transgender people seek to modify their bodies according to their gender perception. In this way, the present work aims to identify in the recent audiovisual productions how transgender people interpret and indicate their journey confirming the perspective defended by Erving Goffman. Therefore, this work is divided into three sections. The first section introduces a general theoretical foundation on the transgender context. The second section presents the relation between transgender persons and their perception of their self-identity. The last section elucidates the means used by transgender people to adjust their image in accordance with their identity, improving their feelings toward themselves and their acceptance by the society.
\end{abstract}

Keywords: Transgender. Self-identity. Stigma. Body modifications.

1 As autoras agradecem as observações e as sugestões da Dra. Jesana Batista Pereira e da Ms. Thalita Carla de Lima Melo do curso de Psicologia do Centro Universitário Tiradentes (UNIT/AL), assim como as sugestões dos pareceristas.

\footnotetext{
Ana Carolina Ferreira Silva

Centro Universitário Tiradentes (UNIT)

E-mail: karolferro@gmail.com

Bárbara Loureiro Gois Cavalcante

Centro Universitário Tiradentes (UNIT)

E-mail: barbara_cavalcante_@hotmail.com

Clarice Acosta Duarte

Centro Universitário Tiradentes (UNIT)

E-mail: clariceduarte@yahoo.com.br

Lorena Madruga Monteiro

Centro Universitário Tiradentes (UNIT)

E-mail: lorena.madruga@gmail.com
} 


\section{Introdução}

O presente trabalho aborda a questão da identidade do eu reproduzida pelas trajetórias dos sujeitos trans nos documentários recentes. Transgênero são pessoas que possuem a percepção de pertencer a um gênero que não condiz com o atribuído pela sua genitália de nascimento. Nesses casos, o sentimento de discordância entre o sexo biológico e o gênero geralmente é experimentado pelo indivíduo ainda na infância. Jesus (2012) complementa que uma parte das pessoas transgênero reconhece essa condição desde pequenas, justificando a possibilidade de ocorrer tardiamente pelas mais diferentes razões, em especial por motivos sociais.

A não identificação com o estereótipo conferido desde tenra idade impulsiona o transgênero à busca por expressões que remetem as manifestações do gênero oposto, como forma de integrar seu corpo à sua identidade do eu ideal. Para essa finalidade, recorrem a recursos diversos para configurar-se conforme sua autopercepção: uso de roupas, tratamentos hormonais e procedimentos cirúrgicos (JESUS, 2012). Tais modificações apresentamse como medidas corretivas para adequar seu corpo com a imagem de gênero que tem de si.

Goffman (1988) traz o conceito de identidade do eu como sendo a percepção do indivíduo sobre ele mesmo a partir de como o outro, seu semelhante, o enxerga, percebe e espera de sua conduta. $\mathrm{O}$ autor aborda isso a partir da concepção do conceito de estigma - "situação do indivíduo que está inabilitado para a aceitação social plena" (GOFFMAN, 1988, p. 04). Nessa conjuntura, compreendese que existe um movimento social de afastamento/exclusão de uma pessoa pela sociedade devido a mesma não possuir características padronizadas como normas.

No caso dos indivíduos trans, por não se adequarem às normatividades estabelecidas pela sociedade, onde gênero é definido pelo sexo do nascimento, esses sofrem estigmatização no meio que se insere. Como consequência disso, buscam fazer modificações em seu corpo como forma de conciliá-lo à percepção que têm de si em relação a seu gênero e incluir-se socialmente.

Além disso, mesmo com as dificuldades frente ao enfrentamento social, os transgêneros também são impulsionados a buscar uma forma de atender sua necessidade de modificar sua imagem para sua satisfação social e existencial. Figueiredo (2006) confirma que a questão da autoestima, da satisfação pessoal, está diretamente relacionada com o corporificar desta imagem; e complementa que a satisfação pessoal, representada pela tão proferida autoestima, se apresenta como argumentação central das quais transgêneros se referem acerca de suas práticas corporais, onde dor e prazer encontram-se na mesma esfera.

Com base no exposto, compreende-se que as modificações corporais revelam ser um ponto central para muitos transgêneros, uma vez que estes buscam cada vez mais possuir atributos considerados naturais para determinado gênero com o intuito de favorecer seu senso de identidade do eu. Lançando-se na busca pela materialização dos seus desejos, percorrem caminhos de sofrimento e vulnerabilidade, que quando colocados na balança se apresentam como inferiores em relação à adequação e satisfação pessoal que pode ser proporcionada. Por esse ângulo, o objetivo desta análise foi identificar, nas produções audiovisuais recentes, como os transgêneros interpretam e significam suas trajetórias ratificando sua identidade do eu sob a perspectiva de Erving Goffman. Ou seja, como eles enfrentam essa condição, focando em suas modificações corporais como forma de adequar sua identidade desejada ao corpo para se sentirem realizados e aceitos por si e pela sociedade.

A escolha por este teórico se deu devido a seus estudos acerca das pessoas em seu cotidiano, em contexto de interação social, e principalmente pela possibilidade de identificar em sua teoria aspectos subjetivos destes sujeitos, como sua identidade e performance. Isto é, a particularidade de cada pessoa frente às interações sociais. Através das falas dos transgênero nos documentários foi possível observar a forma como esses percebem e vivenciam sua identidade do eu, além de como eles lidam com a estigmatização.

Destaca-se que alguns sujeitos trans se auto denominam transgêneros e outros transexuais. Adiferenciação ocorre quando as pessoas transgêneros exprimem o desejo de modificar seus genitais, estas são, além de transgêneros, transexuais. Portanto, todo transexual é transgênero, mas nem todo transgênero é transexual.(LANZ, 2015)

Os documentários, como meio para analisar o objeto do trabalho, foram escolhidos por os mesmos terem como finalidade descrever a representação da realidade e influenciar o receptor na forma como o mesmo percebe o 
mundo. Neles são compartilhados, através de indivíduos reais, em seus ambientes cotidianos, a verdade, o que de fato existe. Sobre isso, Penafria (1999) afirma que ele é um gênero que estimula a reflexão de seu telespectador sobre o mundo.

Para a seleção dos mesmos foram levados em consideração alguns critérios: serem produções recentes (últimos cinco anos); abordarem a temática transgeneridade; possuir transgêneros falando sobre suas vivências; e apresentar falas que identifiquem assuntos como modificações corporais (hormonização e intervenções cirúrgicas), identidade do eu e estigma. Dos documentários selecionados, não foram utilizadas falas de todos os indivíduos trans, considerou-se apenas aqueles que vivenciam o gênero como identidade, ou seja, parte intrínseca do ser; e excluídos aqueles que vivenciam como funcionalidade, como as crossdressers, drag queens, drag kings e transformistas (JESUS, 2012).

Escolheram-se cinco documentários que se adequaram aos critérios citados acima. Apesar da discrepância em relação às produções selecionadas - de grande produção e menor produção -, a escolha se deu pelas que abordavam falas pertinentes ao nosso objeto de estudo. Os selecionados foram: Humanos, Tabu Brasil: mudança de sexo, Transgêneros: a vida além da identidade, Liberdade de Gênero e Protagonismo Trans, todos disponíveis no site youtube. Estas produções abordam, a partir de pessoas transgênero, suas histórias e vivências: questões de nomenclaturas, situações de preconceito, aceitação ou não da família, além de sua descoberta como transgênero até sua transformação corporal como forma de adequação de gênero e melhor percepção de sua identidade do eu. Segue a tabela abaixo para melhor visualização:

\begin{tabular}{|c|c|c|c|}
\hline Documentários & $\underline{\text { Tempo }}$ & $\underline{\text { Falas utilizadas }}$ & $\underline{\text { Ano }}$ \\
\hline $\begin{array}{c}\text { Tabu Brasil: mudança de } \\
\text { sexo }\end{array}$ & 44’34”' & João, Maitê e Carol & 2013 \\
\hline Humanos & $35 ’ 37^{\prime \prime}$ & $\begin{array}{l}\text { Leonarda, João, } \\
\text { Vivian, Laysa e } \\
\text { Letícia }\end{array}$ & 2013 \\
\hline Protagonismo Trans & $58 ' 24 ”$ & $\begin{array}{l}\text { Bruna, Vanessa, } \\
\text { Michelly. }\end{array}$ & 2015 \\
\hline $\begin{array}{c}\text { Transgêneros: a vida além } \\
\text { da identidade }\end{array}$ & $32^{\prime} 16^{\prime \prime}$ & $\begin{array}{l}\text { Luan, Danieli, } \\
\text { Alessandra, Erik, } \\
\text { Victor }\end{array}$ & 2016 \\
\hline Liberdade de Gênero & $223^{\prime} 3^{\prime \prime}$ & Amanda & 2016 \\
\hline
\end{tabular}

Para analisar tais documentários utilizou-se da análise de conteúdo como método de investigação. Campos (2004) expõe que este tipo de análise tem como objetivo a produção de inferência sobre as mensagens dos documentos analisados. Produzir inferência é dar relevância teórica sobre as mensagens analisadas. Nesse caso, estas mensagens são comparadas a informações já verdadeiras, embasando-as em pressupostos teóricos a partir de um contexto histórico e social de sua produção, no caso específico do objeto de análise. Portanto, para a construção de toda análise realizou-se pré-análise; exploração do material; tratamento dos resultados, inferência e a interpretação dos dados (BARDIN, 1997).

Em virtude do exposto, este artigo estrutura-se em três partes. A primeira apresenta um recorte teórico acerca do universo trans em seus aspectos mais gerais como forma de introduzir o assunto. Na segunda é exposta a relação entre os indivíduos transgênero com seu modo de perceber e identificar sua identidade do eu, a qual embasou a pesquisa. E por fim, na terceira são demonstrados os recursos utilizados pelos sujeitos trans como forma de adequar sua imagem a sua identidade desejada, se sentindo melhor consigo mesmo e mais aceito pela sociedade. Nos três tópicos foram colocadas as falas dos transgêneros como forma de ilustrar a teoria. Acredita-se que esse esforço analítico, embora não esgote o tema, pelo contrário, promoverá o protagonismo do sujeito trans a partir da percepção da sua identidade do eu, ou seja, dar visibilidade a realidade desses sujeitos para além das produções audiovisuais.

\section{O Universo Trans Reproduzidos nos Documentários}

A compreensão acerca do universo transgênero aparece como um assunto complexo para a maioria das pessoas. Muitas vezes a questão de gênero é confundida com orientação sexual, sendo comum pensar que a pessoa trans se caracteriza para determinado gênero por conta da sua preferência sexual, deixando de perceber que isso tem a ver com identidade. Esta confusão é experimentada inclusive pelos próprios sujeitos trans, durante a sua descoberta:

"O começo da experiência é sempre curioso, porque primeiro eu achei que eu fosse gay pelo fato de sexualmente 
me sentir atraída por homens" (Humanos: Leonarda, $\left.04^{\prime} 05^{\prime \prime}\right)$.

Essa questão da identidade de gênero está relacionada à percepção subjetiva que um indivíduo tem de si como masculino, feminino ou "ainda uma mescla de ambos, independentemente do sexo biológico e de orientação sexual" (SECAD, 2007, p. 19). Dentro dessa abordagem, discute-se que entre a maioria das pessoas existe uma concordância entre corpo anatômico e a representação psíquica desse corpo, ou seja, geralmente a identificação das características de gênero corresponde ao sexo biológico. No entanto, existe um grupo significativo de sujeitos que não experimentam essa relação, os denominados transgênero.

"Me olhando no espelho eu não gostava, porque dai eu via que era de menino e não de menina, eu quando criança não tinha nem de querer tocar porque causava repugnância, tinha uma sensibilidade muito grande nele, nem passar muito sabonete, nada..." (Tabu Brasil: mudança de sexo, Maitê, l'13').

"Eu me identificava com o gênero masculino, eu desejava ser um menino, era o pedido que eu fazia todas às vezes diante da velinha do bolo de aniversário, eu quero ser um menino como os outros" (Tabu Brasil: mudança de sexo, João, 2'34’”).

Apesar dessa diferenciação do posicionamento de gênero em relação à população trans e a grande parte das pessoas, concebe-se que o processo de formação de identidade ocorre de maneira comum a todos. $\mathrm{O}$ que se diferencia é o fato de que pessoas transgênero "não se identificam, em graus diferentes, com comportamentos e/ ou papéis esperados do gênero que lhes foi determinado quando de seu nascimento" (JESUS, 2012, p. 14), e que isto implica enfretamentos sociais, uma vez que esse grupo foge do que é considerado padrão.

“Ali pela adolescência eu comecei a ter ideias e vontades e perceber que eu não era bem da maneira como as pessoas achavam que eu fosse" (Humanos, Leonarda, 1'17').
O desenvolvimento de identidade de gênero ocorre ao longo da vida do sujeito sofrendo influência de fatores genéticos, hormonais e psicológicos, além das circunstâncias sociais e culturais que o indivíduo se insere. Essa parte do desenvolvimento está relacionada com a percepção que o indivíduo tem sobre si e seu papel no mundo, se apoiando em comportamentos e atitudes relacionadas com cada gênero sexual (DIEHL; VIEIRA, 2013). Isso significa que durante esse percurso ocorre ao sujeito uma assimilação quanto a seu sexo e seu gênero, podendo estes não estar em concordância.

Ao se referir na questão do sexo de um indivíduo, está sendo considerado seu composto biológico e genético. Nesse sentido, ele é dito como macho ou fêmea a partir de sua anatomia genital. Já ao se falar de gênero, compreende-se como a identificação que o sujeito tem de si, reconhecendo-se como masculino ou feminino, independentemente da anatomia de sua genitália. Martinez-Guzmán (2012) resume esta ideia trazendo que o sexo é entendido como corpo ligado à sexualidade, e gênero como identidade composta por significados e possibilidades interpretativas.

Sobre a vivência da identidade de gênero da população trans, Silva e Cerqueira-Santos (2014, p.35) apontam as dificuldades enfrentadas por este grupo:

O enfrentamento da estereotipia de gênero, do estigma e do preconceito da condição de sujeito desviante em relação à sua sexualidade, além da falta de suporte e amparo social por parte da maioria dos grupos aos quais estes indivíduos integram. Diante de tais fatores, estes sujeitos seriam consequentemente considerados "anormais", o que leva a uma repercussão negativa na identidade deste grupo, pois muitos(as) querem ser reconhecidos(as) enquanto mulheres (no caso de trans femininas) ou como homens (nos casos de trans masculinos).

Portanto, compreende-se que o senso que envolve a relação de identidade e gênero não se relaciona apenas à individualidade de cada uma dessas pessoas, de como ela se percebe de forma particular, logo se entende que também existe uma necessidade de reconhecimento e pertencimento por seu contexto social, por isso é possível afirmar que o senso de identidade de cada sujeito é inerente 
à sua interação com o outro. Nesse sentido, na perspectiva de Goffman, "o reconhecimento de si próprio carece do reconhecimento do outro" (PICOLLO; MENDES, 2012, p. 50), ocorre que há um reconhecimento de si no outro e, em conjunto, dos outros em si mesmo.

Para sentir-se reconhecido e aceito pela sociedade, os transgênero despontam a iniciativa de modificar sua figura para transparecer cada vez mais a imagem do gênero que se reconhece, tentando ocultar qualquer vestígio que possa denunciá-lo como "desviante". Sobre essa questão, Butler (2009) explana que a decisão da transformação corporal é dificultada pelo preconceito, uma vez que nas rígidas condições sociais atuais, nas quais as normas de gênero ainda são apresentadas seguindo maneiras convencionais, os desvios da norma são vistos como suspeitos. Dessa maneira, na tentativa de poupar-se do estigma e configurar-se conforme sua autopercepção, esse grupo recorre a diversos recursos: utilização de roupas, tratamentos hormonais e procedimentos cirúrgicos para o sexo oposto ao qual nasceu.

"Para mim é um reconhecimento social mesmo, que aí é o menino, tem a voz grossa e os trejeitos do rosto também mudando, mas esse reconhecimento social é bastante importante, até porque o meu periodo de transição foi dentro da faculdade" (Transgêneros: a vida além da identidade, Victor, 19'54").

"Eu acho que sou uma senhora bem aceitável, bem passável. É um conforto intimo que você não imagina." (Humanos, Letícia, 16’08”).

"A primeira cirurgia que faz um trans homem é tirar os seios que é um grande alivio social e depois vem a histerectomia que é a retirada dos órgãos internos reprodutores que também dá um grande alívio na medida em que você deixa de produzir o estrogênio e passa a tomar testosterona, portanto os caracteres sexuais secundários como a barba, a voz, enfim, a musculatura, há varias mudanças com a testosterona" (Humanos, João, 15'29").

"Deixar o cabelo crescer foi uma pontinha desse iceberg que eu já botava para fora” (Humanos, Vivian, 10`47”).
Conforme as falas mencionadas, cada sujeito trans terá um modo particular de configurar sua identidade pessoal pelas relações com os outros e com o mundo, e esta identidade vai se constituir pelo seu senso de pertencimento ou não a determinado gênero. $\mathrm{O}$ que muda no percurso da formação de identidade entre os sujeitos trans e a outra parte das pessoas é o sentimento contínuo de mal-estar com a anatomia corporal e o seu senso de identidade, podendo levá-lo a uma constante busca de integração do corpo e o gênero percebido. Essa busca também sofre influência da sociedade neste contexto.

\section{'Identidade do Eu' das Pessoas Trans}

A sociedade a qual o indivíduo está inserido é responsável pelo comportamento do mesmo e de todos os outros, e pela a construção de suas identidades. Ela tem maior força e está acima do indivíduo, pois o mesmo é produto de seu meio. Berger e Luckman (2004, p. 217) escrevem que

A socialização produz identidades, que são socialmente pré-definidas e delineadas em alto grau. Uma vez que cada indivíduo se defronta com o mesmo programa institucional para sua vida na sociedade, a força total da ordem institucional é levada a pesar de modo mais ou menos igual sobre cada indivíduo, produzindo a maciez coercitiva da realidade objetiva que deve ser interiorizada.

Sendo ele um ser social, durante toda sua vida troca informações com os outros, se construindo a partir dessas interações. Nesse sentido, Myers (2000) escreve que as pessoas influenciam umas as outras através dos relacionamentos entre si. Ou seja, elas são influenciadas pelos valores e crenças vindos da sociedade em geral, através do contato pelo seu cotidiano, e acabam frequentemente reproduzindo esses pensamentos em forma de comportamentos e atitudes.

Durkhein (2007), primeiro teórico a contribuir de forma científica sobre o estudo da interação social, considera que o indivíduo é desconsiderado no seu ponto de vista individual em relação à sociedade, pois existe neste contexto uma coerção social, onde ele acaba sendo pressionado a agir e pensar de uma determinada maneira. 
Quando este de fato toma posse essas características, está formando sua identidade social (GOFFMAN, 2011).

No caso dos sujeitos trans, é esperado pela sociedade que sigam um padrão de comportamentos e atitudes de acordo com seu corpo (genital). Estas pessoas descobrem desde pequenas que estão em desacordo com o esperado, e na sua infância acabam muitas vezes representando aos outros o que eles esperam da mesma, até não conseguir mais. No caso das mulheres trans, elas na infância tendem a utilizar roupas masculinas e se comportar como menino, além das brincadeiras consideradas masculinas; enquanto os homens trans tendem a utilizar roupas de meninas, se comportar como tal e brincar com meninas de brincadeiras consideradas femininas.

"Eu comecei a tentar imitar o meu irmão em tudo, então o meu irmão fazia uma coisa e eu tentava imitar ele. Botei ele como exemplo a ser seguido, para que eu não tivesse problema, não fosse objeto de chacota, e para que meu dia a dia e da minha familia, das pessoas que tavam perto de mim fosse mais tranquilo por conta disso" (Tabu Brasil: mudança de sexo, Maitê, 9'30").

"Eu não entendia, eu simplesmente não entendia porque que eu era tripudiado, porque que eles não deixavam eu fazer aquilo que eu queria, ou aquilo que me dava mais prazer, ou o brinquedo com o qual eu me sentia mais confortável" (Humanos, Letícia, 2'22”).

"Na minha cabeça eu tinha um problema mesmo por eu querer ser assim, por eu ser assim, então eu me isolava de tudo, vivia só nos vídeo games sempre escolhendo personagens femininos, mas fora desse mundinho eu tinha que ser o menininho" (Liberdade de gênero, Amanda, 2'41").

"Eu fui saber de hormônio e procurar saber de hormônio depois dos 20 anos, porque ate então eu tava tentando sublimar tudo isso e tentar viver de uma forma que fosse mais aceitável pela sociedade, ou seja, viver interpretando um menino homossexual" (Humanos, Laysa, 11 '23").

Esses trechos exemplificam o que Goffman (2011) escreve sobre representações, por uma perspectiva teatral, em seu livro: a representação do eu na vida cotidiana. Para ele, as pessoas representam um papel de si mesmo para os outros em seu cotidiano, e acabam acreditando nesta performance como realidade. É esperado pela sociedade determinados comportamentos e posturas dos indivíduos, e cabe a este interpretar esses papéis sociais para os outros. A crença nesses desempenhos reforça ainda mais a identidade do mesmo.

No caso dos transgêneros, eles já nascem com a percepção de pertencer ao gênero oposto ao de seu nascimento, por mais que muitas vezes representem estar de acordo com o gênero atribuído por seu genital, sofre subjetivamente por não se identificar com isso, portanto ele já possui uma identidade. Neste caso, esses desempenhos a reforçam ainda mais, pois os mesmos avigoram seu desejo de pertencerem ao gênero oposto, fazendo com que, primeiramente às escondidas, utilizem objetos e reproduzam comportamentos do gênero que acreditam pertencer, e posteriormente, começam a transformar seu corpo, através de hormonização e cirurgias, para aliviar esse sofrimento.

"Era uma prazer, uma catarse imensa assim eu brincar com coisas que meninas brincariam, era tipo uma felicidade, era uma coisa tremenda" (Humanos, Vivian, 2'12”).

"Toda aulinha de futebol eu ia de cueca, não ia de calcinha porque era o momento que eu tinha tipo para ser o menininho" (Transgêneros: a vida além da identidade, Luan, 1'22").

"Eu sempre brinquei muito de futebol, lutinha com meu primo. Nunca gostei de usar saia, vestido, rosa. Sempre foi bermuda, camisetão, chuteira no pé, machucado espalhado pelo corpo inteiro. Sempre gostei mais dessas coisas consideradas masculinas" (Transgêneros: a vida além da identidade, Luan, 5'42”).

"Sempre me sentindo mais ligado ao universo das coisas tidas como masculinas, brincadeiras, roupas" (Transgêneros: a vida além da identidade, Erik, 3'39").

"Eu sempre me achei mulher, eu brincava de boneca, eu ganhava carrinho, não queria brincar de carrinho" (Tabu Brasil: mudança de sexo, Carol, 4'55”). 
Com as falas acima, identifica-se que os sujeitos trans, em algum momento, já se comportavam de acordo com sua identidade desejada. Esta, por sua vez, tem a ver com a subjetividade do próprio indivíduo (como ele se percebe) e também com sua relação com seu meio (como ele percebe o mundo e tem a noção de feminino e masculino a partir da interação com a sociedade). Complementando esta ideia, Berger e Luckman (2004, p. 228) escrevem que a identidade também "é formada por processos sociais", dado que "uma vez cristalizada, é mantida, modificada ou mesmo remodelada pelas relações sociais". Percebe-se, assim, que essa identidade é construída a partir da relação com o outro. Novaes (1993, p. 111), nesse sentido, traz que "esta reflexão sobre si provocada pelo contato com o outro, implica o confronto entre estes sistemas de valores, a partir dos quais se especula sobre si e os outros". É experimentado pelos transgêneros esse questionamento interior sobre sua condição perante a sociedade.

"Percebi que eu era diferente muito cedo assim. Lá pelos cinco anos eu já percebia que tinha algo fora do que a sociedade esperava" (Humanos, Vivian, 1'05").

A partir desta noção de identidade, Goffman (1988) traz o conceito de identidade do eu, em seu livro estigma, que sintetiza tudo aqui já citado. Segundo o autor, a identidade do eu é "o sentido subjetivo de sua própria situação e sua própria continuidade e caráter que um indivíduo vem a obter como resultado de suas várias experiências sociais" (p. 91). Ou seja, é a verdadeira identidade do indivíduo, que é influenciada, remodelada e construída pela identidade social e pela identidade pessoal - forma como os outros percebem e definem o sujeito -. É o modo como o indivíduo se percebe a partir do olhar do outro sobre ele (como o enxerga, percebe e espera de sua conduta), observando e escolhendo aquilo que melhor the define, durante a interação de ambos.

"Nós temos o espírito feminino dentro de nós, é uma coisa que vem de dentro" (Protagonismo trans, Vanessa, $\left.19^{\prime} 05^{\prime \prime}\right)$.

"Eu nasci com o gênero masculino. Era muito estranho eu me olhar no espelho e não me reconhecer. Queria ser uma mulher igual a minha mãe, igual a minha irmã”.
(Liberdade de gênero, Amanda, 00'50”).

"A coisa do corpo, eu não queria me relacionar com um homem sendo homem, tendo um corpo de homem. Como eu me sentia mulher e sou mulher, o meu problema tava no meu corpo e não no corpo do outro" (Humanos, Leonarda, 16'27'”).

"Eu não me considero uma transexual, eu me considero uma mulher" (Protagonismo trans, Vanessa, 18'37”).

"A minha cabeça é de uma mulher, eu sou uma mulher, tenho meus laudos, fiz tratamento durante dois anos..." (Protagonismo trans, Bruna, 2'45").

Percebe-se, portanto, que essas inter-relações podem ser positivas, mas também muito negativas no que se trata de pessoas que não se consideram aceitas como se sentem. As pessoas transgênero constroem e remodelam essa identidade do eu geralmente a partir do estigma sofrido pela sociedade por sair do padrão instituído pela mesma. Mesmo tendo certeza de quem são, esses indivíduos necessitam se adequar às características do gênero que se reconhecem de fato, como forma de se sentirem verdadeiros e completos, além de respeitados e aceitos por seu meio social.

\section{Estigma e Modificações do Corpo}

A marginalização social percorre a história humana desde tempos antigos, quando diversas culturas estipulavam status morais e sociais os quais o indivíduo deveria seguir. Caso alguém não se adequasse a tais conjunturas, este seria desclassificado e estigmatizado. $\mathrm{Na}$ Grécia antiga, o termo estigma foi criado para evidenciar sinais corporais nas pessoas, atribuindo-as status de algo extraordinário ou mau sobre o status de quem os apresentava (GOFFMAN, 1988). Quando representava uma característica ruim, a pessoa marcada deveria ser evitada, principalmente em lugares públicos.

Goffman (1988), ao empregar tal termo referindose a atributo depreciativo, faz pelo lado negativo da palavra. No contexto atual, pode-se afirmar que a população trans vivencia o estigma nesse modo pejorativo e de exclusão, e isto é observado pela grande estigmatização em relação a 
esse grupo por divergirem do que a sociedade estabelece em relação à concordância entre gênero e sexo.

Podem-se mencionar três tipos de estigma nitidamente diferentes. Em primeiro lugar, há as abominações do corpo - as várias deformidades físicas. Em segundo, as culpas de caráter individual, percebidas como vontade fraca, paixões tirânicas ou não naturais, crenças falsas e rígidas, desonestidade, sendo essas inferidas a partir de relatos conhecidos de, por exemplo, distúrbio mental, prisão, vício, alcoolismo, homossexualismo, desemprego, tentativas de suicídio e comportamento político radical. Finalmente, há os estigmas tribais de raça, nação e religião [...] (GOFFMAN, 1988, p. 7).

Nessa passagem, fazendo análise do estigma na realidade trans, observa-se que essas pessoas o sofrem a nível de "abominações do corpo", uma vez que a corporificação da imagem os leva a um estereótipo que despertadesconfiança epreconceito.Eemrelaçãoàs "culpas de caráter individual", ao serem consideradas pessoas de atitudes desqualificadas e imorais. A discriminação por parte da sociedade é lançada de variadas formas - insulto, violência, discriminação, piada, exclusão, etc.-, trazendo dificuldade a essas pessoas quando tentam vivenciar sua identidade no meio social. Isto é melhor visualizado nas falas abaixo:

"Isso mexe com a nossa auto-estima, às vezes a gente se olha no espelho, tá se sentindo bem, e sai na rua e dizem olha o travecão, vira homem" (Liberdade de gênero, Amanda, 9'48').

"Para muitos ignorantes eu sou uma aberração da natureza, pra outros eu sou um objeto sexual, um fetiche, porque eu sou uma mulher transexual" (Liberdade de gênero, Amanda, 13'41").

"Era eu entrar na escola e todo mundo cochichando, ficavam olhando para mim" (Liberdade de gênero, Amanda, 3'49").

"Nasce um homem, se transfigura totalmente como uma mulher, mas não é na cabeça deles, porque levam travesti, como travesti, veado, gay, como se fosse tudo a mesma coisa, independente de estar vestido de homem, é gay [...] tudo igual" (Protagonismo trans, Michelly, 24'52").

"Eu sai de vestido longo, bonito, de gala, e eu sai toda produzida para os lugares que eu sabia que as pessoas iam me ver daquela maneira, tava me sentindo maravilhosa, linda, poderosa e as pessoas me vendo totalmente esquisita, aquele ser totalmente andrógino" (Humanos, Laysa, 9'03').

A análise das consequências de se viver nessas condições de rotulação e discriminação pode ser contemplada a partir da concepção de identidade do eu. Goffman (1988, p. 91-92) reproduz que "a ideia de identidade do eu nos permite considerar o que o indivíduo pode experimentar a respeito do estigma e sua manipulação, e nos leva a dar atenção especial à informação que ele recebe quanto a essas questões". Ou seja, a identidade do eu se relaciona com a forma como o indivíduo trans percebe e vivencia as informações advindas da sociedade frente a seu estigma.

Grande parte dos transgêneros termina vivenciando essas situações de maneira negativa. Moreno (2010) tece que este grupo sempre termina por ser vítima de chacota por não se enquadrar nos comportamentos esperados pela sociedade e que essa "certamente é uma das fontes de insegurança e insatisfação dos indivíduos, que, por fim, acabam se enxergando como alguém nãoenquadrado e anormal" (p. 43). Como forma de aliviar estes sentimentos e o desfavorecimento das relações por parte do seu estereótipo, eles são levados a buscar progressivamente tentativas de configurar seu corpo ao gênero percebido. É uma tendência necessária de se sentir mais a vontade consigo e com o meio, esperando uma melhor aceitação de si e da sociedade.

A característica central da situação de vida, do indivíduo estigmatizado pode, agora, ser explicada. É uma questão do que é com frequência, embora vagamente, chamado de "aceitação". Aqueles que têm relações com ele não conseguem lhe dar o respeito e a consideração que os aspectos não contaminados de sua identidade social os haviam levado a prever e que ele havia previsto receber; ele faz eco a essa negativa descobrindo que alguns de seus atributos a garantem (GOFFMAN, 1988, p. 11). 
Goffman (1988), portanto, aponta que o indivíduo estigmatizado tenta corrigir o que considera a base objetiva do seu defeito como forma de conseguir uma melhor aceitação por si mesmo e consequentemente pelos outros. Assim os transgêneros começam a mudar suas características físicas, partindo de transformações que começam pelas roupas e cabelo, até a hormonização e cirurgias de pequeno e grande porte (redesignação sexual).

"Eu preciso da cirurgia pra me sentir plena, pra me sentir eu. Eu acho que só a partir desse momento que eu vou olhar e vou dizer, essa é a Carol" (Tabu Brasil: mudança de sexo, Carol, 18'30").

"Eu vou fazer a cirurgia pelo meu bem estar físico e psicológico, o meu corpo pede isso" (Protagonismo trans, Bruna, 21'30").

"Decidir fazer a transição já é um indicio de que você não aguenta mais viver naquele corpo" (Transgêneros: a vida além da identidade, Danieli, 6'11').

"Eu comecei a me hormonizar com quinze anos de idade, eu juntava dinheiro para comprar meus hormônios, tomava meus hormônios escondida e foi assim que eu comecei com o processo" (Transgêneros: a vida além da identidade, Alessandra, 18'35').

"Eu fiz prótese de silicone e a cirurgia de redesignação sexual, eu me senti realmente operada depois de uns dois meses, quando eu consegui me olhar no espelho e tava tudo bonitinho" (Transgêneros: a vida além da identidade, Alessandra, 24'41").

Observa-se a partir das falas acima a ideia da necessidade da cirurgia de redesignação sexual como meio de corrigir seu maior estigma (órgão genital), no entanto, esse tipo de procedimento cirúrgico nem sempre é uma opção para todos eles. Sobre isso, Bento (2006, p. 44) escreve:

O que faz um sujeito afirmar que pertence a outro gênero é um sentimento; para muitos transexuais, a transformação do corpo por meio de hormônios já é suficiente para lhes garantir um sentido de identidade, e eles não reivindicam, portanto, as cirurgias de transgenitalização.
"No meu caso, eu não tenho vontade de operar, eu não tenho nem coragem realmente de cortar o mal pela raiz não, eu tô bem assim como eu tô" (Protagonismo Trans, Michelly, 20'25').

Deste modo, é possível considerar que tanto nos casos de redesignação sexual ou de desinteresse por este tipo de procedimento, a satisfação pessoal torna-se centralidade no processo de subjetivação do indivíduo trans, onde qualquer mudança física que eles façam passa a transmitir neles um sentimento de plenitude e bem estar físico e psicológico. Também se pode afirmar que as categorias de identidade, subjetividade e corpo são vividas de forma entrelaçadas.

"Eu me construo da maneira que eu consigo melhor me enxergar” (Humanos, Leonarda, 23 '08”).

Visto tudo o que foi exposto, percebe-se que os aspectos: estereótipo, estigmatização, modificação corporal, forma como o indivíduo lida com seu estigma - sempre a partir do contexto social - estão presentes no processo de constituição da identidade do eu das pessoas trans. Ressalta-se, pois, que a identidade do eu se forma a partir do ponto de vista do sujeito através da sua interação com o próximo e sua inserção na sociedade.

\section{Considerações Finais}

As pessoas transgênero nos fazem ressignificar o modelo de sociedade ao qual vivemos. Elas revelam a diversidade, confrontando com o paradigma social, que por sua vez, valoriza a homogeneização, desqualificando e excluindo aquilo que é diferente. As identidades trans, quando expressadas na sociedade, tendem a empurrar os sujeitos à estigmatização e ao preconceito, que determinam uma posição de desvantagem nas relações. Este processo repercute no modo como essas pessoas vivenciam sua identidade do eu dado que sua percepção de si parte do olhar do outro. Ficou evidente que elas passam por diversas configurações da sua imagem como forma de corporificar sua identidade.

No cenário atual, em que os valores sociais começam a serem repensados, onde as pessoas tem maior liberdade de expressão e as informações são mais 
propagadas, as produções audiovisuais ganharam espaço para debater questões de gênero e sexualidade na tentativa de desconstruir princípios e desnaturalizar representações de padrões quanto a esses assuntos. O documentário como meio de imergir no universo trans nos possibilitou analisar as singularidades dessas pessoas através de suas falas, no entanto foi reconhecido que as produções pouco exploram sua subjetividade, sem aprofundar como os indivíduos trans se sentem e vivenciam suas experiências, dando enfoque somente em relatos de fatos.

Também foi identificado durante a seleção dos documentários, que os mesmos discorrem sobre conteúdos diversos, demonstrando vários aspectos da vida dos sujeitos trans, sem se direcionar e aprofundar em algum tema específico. Devido a isso, a escolha desses materiais foi dificultada, foi preciso assistir diversos documentários com análise imediata das falas para selecionar os que mais auxiliavam para o nosso objeto de estudo.

A realidade apresentada coloca que é de suma importância o olhar para a população trans, uma vez que a necessidade de construir uma identidade compromete sua convivência no meio social através do estigma. É fundamental analisar como se constrói o processo subjetivo dessas pessoas devido ao sofrimento existente por trás de cada história. Foi alcançado que existem dimensões sociais e pessoais na identidade das pessoas transgênero. No caso da identidade do eu, sempre são considerados os interesses e definições da sociedade em relação a esses indivíduos, no entanto é lançada uma questão subjetiva do sujeito a respeito de sua identidade, julgando que tem condições para construí-la.

A respeito da associação entre as falas expostas com a teoria de identidade do eu de Goffman, pôde-se observar que apesar da dificuldade na seleção dos documentários, a seleção das falas foi mais acessível, pois elas além de dialogarem muito bem com a teoria, também facilitaram ainda mais a compreensão da mesma como forma de exemplificá-la. Com isso, se conseguiu identificar a esfera da identidade do eu a partir da realidade de um grupo específico de indivíduos, no caso deste trabalho, os transgênero.

Por fim, este trabalho é uma forma de esclarecer um pouco mais sobre a população trans, favorecendo reputação dessas pessoas para que detenham espaço na sociedade, sendo protagonistas de sua trajetória. Sugerem-se, outros estudos de orientação semelhante, para que sejam aprofundados cada vez mais os aspectos subjetivos deste grupo, através de entrevistas, e produções de novos documentários mais completos e direcionados para um único assunto.

\section{Referências}

BARDIN, L. Análise de conteúdo. Lisboa: Edições 70, 1997.

BENTO, B. A reinvenção do corpo: sexualidade e gênero na experiência transexual. Rio de Janeiro: Garamond, 2006.

\section{BERGER, P. L.; LUCKMANN, T. A construção social} da realidade: tratado de sociologia do conhecimento. 24 . ed. Petrópolis: Vozes, 2004.

BUTLER, J. Desdiagnosticando o gênero. Tradução de André Rios. Physis, v. 19, n. 1, p. 95-126, ago./abr. $2009 .$.

CAMPOS, C. J. G. Método de análise de conteúdo: ferramenta para a análise de dados qualitativos no campo da saúde. Rev. Bras. Enferm., Brasília, v. 57, n. 5, p. 611614, set/out. 2004.

DIEHL, A.; VIEIRA, D. L. Sexualidade: do prazer ao sofrer. São Paulo: Roca, 2013.

DURKHEIM, E. As regras do método sociológico. 3. ed. São Paulo: Martins Fontes, 2007.

FIGUEIREDO, A. Você já ouviu falar na dor da beleza? Experiências, corpo e afetividades na identidade transgênero. Artigo, 2006.

GOFFMAN, E. A representação do eu na vida cotidiana. 18. ed. Petrópolis: Vozes, 2011.

Estigma: notas sobre a manipulação da identidade deteriorada. 4. ed. Rio de Janeiro: LTC, 1988.

Humanos. Produção de Camila Avanço, Lucas Amorim e Rita Groch. Orientação de Joseane Zanchi Daher. Curitiba, 2013. Documentário (35’37”). Disponível em: <https:// www.youtube.com/watch? $\mathrm{v}=81 \mathrm{tQ} 567-\mathrm{j} 9 \mathrm{M}>$. Acesso em: 24 mar. 2017. 
JESUS, J. G. Orientações sobre identidade de gênero: conceitos e termos. 2. ed. Brasília, 2012.

LANZ, Letícia. O corpo da roupa: A pessoa transgênera entre a transgressão e a conformidade com as normas de gênero. Uma introdução aos estudos transgêneros. $2^{\mathrm{a}}$. ed. Curitiba: Transgente, 2015.

Liberdade de gênero. Direção de João Jardim. São Paulo: GNT, 2016. Documentário (22'53”). Disponível em: $\quad<$ https://globosatplay.globo.com/gnt/v/5390079/>. Acesso em: 30 mar. 2017.

MARTINEZ-GUZMÁN, A. Repensar la perspectiva psicosocial sobre el género: contribuciones y desafíos a partir de las identidades transgénero. Psicoperspectivas, Valparaíso, v. 11, n. 2, p. 164-184, set./mai. 2012.

MORENO, B. S. Representações da identidade transexual. Língua, literatura e ensino. Campinas, v. 5, p. 37-45, out. 2010.

MYERS, D. G. Psicologia Social. 6. ed. Rio de Janeiro: LTC, 2000.

NOVAES, S. C. Jogo de espelhos: imagens da representação de si através dos outros. São Paulo: Edusp, 1993.

PENAFRIA, M. A identidade do documentarismo. In: . O filme documentário: história, identidade, tecnologia. Lisboa: Cosmos, 1999. p. 35-56.

PICCOLO, G. M.; MENDES, E. G. Dialogando com Goffman: contribuições e limites sobre a deficiência. Poíesis Pedagógica, Goiás, v.10, n. 1, p.46-63, jan/jun. 2012.

Protagonismo trans. Produção de Luis Carlos de Alencar. Coordenação de Adriana Geisler. Rio de Janeiro: Couro de rato, 2015. Documentário (58'24”) Disponível em: $<$ https://www.youtube.com/watch?v=k4yJ3ZoxaAg $>$. Acesso em: 30 mar. 2017.
SECAD, C. Gênero e diversidade sexual na escola: reconhecer diferenças e superar preconceitos. Secretaria de educação continuada, alfabetização e diversidade (Secad/MEC). Brasília, 2007. Disponível em: <http:// pronacampo.mec.gov.br/images/pdf/bib_cad4_gen_div_ prec.pdf $>$. Acesso em: 15 out 2016.

SILVA, B. B.; CERQUEIRA-SANTOS, E. Apoio e suporte social na identidade social de travestis, transexuais e transgêneros. Rev. da SPAGESP, São Paulo, v. 15, n. 2, p. 27-44, mai./set. 2014.

Tabu Brasil: mudança de sexo. Direção de Kiko Ribeiro. São Paulo: National Geographic Channel, 2013. Documentário (44'34”). Disponível em: <https://www. youtube.com/watch?v=TvcT5XJf8tA>. Acesso em: 23 mar. 2017.

Transgêneros: a vida além da identidade. Produção de Maíra Menequini et al. Orientação de Eliane Basso. São Paulo, 2016. Documentário (32’16”). Disponível em: $<$ https://www.youtube.com/watch?v=WupOPOrH8hw $>$. Acesso em: 24 mar. 2017.

Data de recebimento: 26/07/2017.

Data de aceitação: 20/12/2017. 